\title{
STUDY OF SECONDARY GRAIN GROWTH ON 718 ALLOY
}

\author{
JF Uginet * and B. Pieraggi * * \\ * : Fortech, Pamiers, France \\ ** : ENSCT, Toulouse, France
}

\begin{abstract}
A fine grain microstructure is usually required on 718 engine discs, to improve their resistance to fatigue in service conditions. The refining of typical billet microstructures was extensively investigated elsewhere through different thermomechanical processing (TMP).

This investigation was carried out to characterise the evolution of an initially fine grained microstructure (ASTM index $>8$ ) during a complex thermomechanical treatment, similar to the closed die forging of a disc. The influence on the alloy microstucture of different parameters such as thermal insulation, strain rate, thermal cycles... was investigated. For some specific TMP conditions, an abnormal grain growth was observed. Such a grain growth was referenced as secondary, and lead locally to grains of ASTM index of about 5. The influence of this particular microstructure on the mechanical properties has been investigated through tensile and fatigue tests.
\end{abstract}




\section{$\underline{\text { Introduction and objectives }}$}

Alloy 718 is extensively used for engine disc applications, its mechanical properties can be still increased and controlled through a careful control of its microstructure (1). Indeed, the final properties are fixed by the alloy microstructure. In many applications, fatigue resistance is of major concern and a fine-grained microstructure is required throughout the discs. Thermomechanical treatments, and more specifically close-die forging, permit the control of the alloy microstructure and then to achieve the drastic requirements imposed on the mechanical properties and behavior of gas turbine discs $(2,3)$. Computer modeling provides useful information on material flow, deformation paths, thermal evolution, etc. during the closed die forging. The knowledge of the evolution of alloy microstructure during all the forging and heat treatment steps is necessary. These steps may include ring rolling, blocker, finish closed die forging. During these steps, the local conditions may vary greatly and the associated microstructure may be refined at different steps of the process. It is then important to control the subsequent evolution of a fine grain microstructure during the last stages of the forging (deformation) process. The control of grain size is generally achieved through the pinning action of the intergranular precipitation of $\delta-\mathrm{Ni}_{3} \mathrm{Nb}$ phase formed during working and heat treatments at temperatures under the $\delta$-solvus. However, the intergranular precipitates of $\delta$ $\mathrm{Ni}_{3} \mathrm{Nb}$ are not always sufficient to avoid an evolution of the fine-grained microstructure towards a coarse-grained one. Such an evolution is often observed in specific areas of the forging. The objective of this study was to investigate the main parameters which govern this abnormal or secondary grain growth.

\section{Materials and experimental procedures}

All the experiments were performed on cylindrical specimens $(80 \mathrm{~mm}$ in diameter and $80 \mathrm{~mm}$ long) which were machined out of a forged bar of which the chemical composition, (Table I), is typical of alloy 718 for disc applications. The main characteristic of this forged bar was its initial fine-grained microstructure of ASTM 8.

Table I : Chemical composition (wt.\%) of alloy 718 used in the present work.

\begin{tabular}{|c|c|c|c|c|c|c|c|c|c|c|c|c|c|c|}
\hline $\mathrm{C}$ & $\mathrm{Si}$ & $\mathrm{Mn}$ & $\mathrm{S}$ & $\mathrm{P}$ & $\mathrm{Cr}$ & $\mathrm{Ni}$ & $\mathrm{Mo}$ & $\mathrm{Fe}$ & $\mathrm{Nb}$ & $\mathrm{B}$ & $\mathrm{Ti}$ & $\mathrm{Al}$ & $\mathrm{Cu}$ & $\mathrm{Mg}$ \\
\hline .026 & 0.06 & .04 & .0004 & .002 & 17.5 & 53.5 & 2.9 & 18.7 & 5.45 & .004 & 1.0 & .50 & .05 & .001 \\
\hline
\end{tabular}

The upsetting of the specimens, preheated at $980{ }^{\circ} \mathrm{C}$ for $2 \mathrm{hr}$., was carried out under an hydraulic press with dies preheated at $600^{\circ} \mathrm{C}$. Figure 1 shows the direction and ratio of deformation. After upsetting, three different sections of the deformed cylinders were cut for microstructural investigation after three different heat treatments : i) air cooling after upsetting, ii) solution heat treatment (SHT) at $955^{\circ} \mathrm{C}$ for $90 \mathrm{~min}$ and air cooling, iii) $\mathrm{SHT}$ at $970^{\circ} \mathrm{C}$ for 90 min and air cooling 


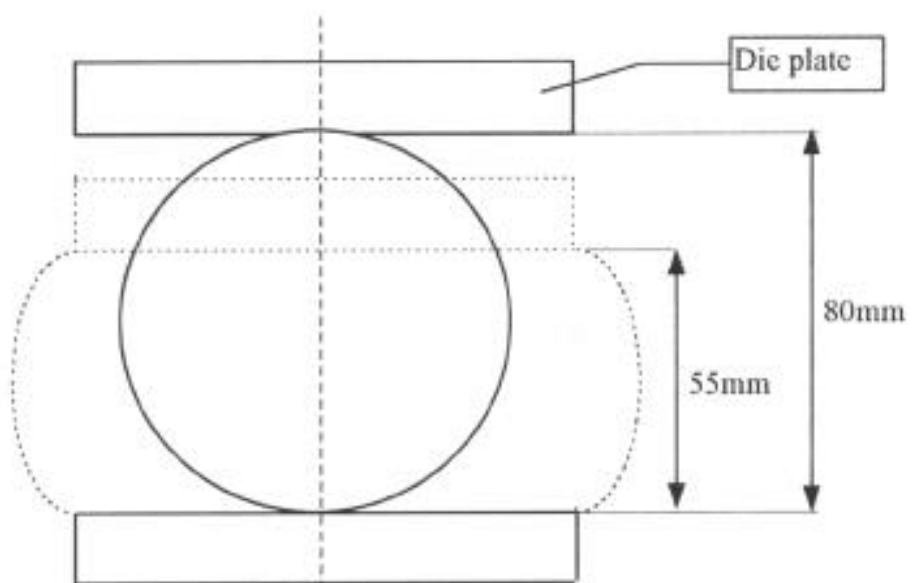

Figure 1 - Direction of upsetting of the billet

\begin{tabular}{|c||c|c|}
\hline Insulation & Ram Speed $(\mathrm{mm} / \mathrm{s})$ & Cycle after deformation \\
\hline None & 1 & Air cooling \\
\hline Intermediate & 7 & $\begin{array}{c}\text { Immediate reheating at } \\
980^{\circ} \mathrm{C} \text { for } 15 \text { min-Air cooling }\end{array}$ \\
\hline High & 14 & - id- \\
\hline
\end{tabular}

\section{Test Modeling}
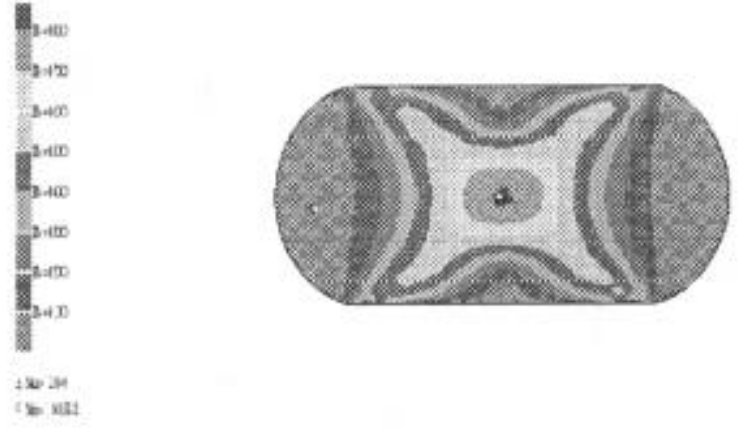

Figure 2 - Deformation Map
After SHT, a double aging at 720 and $620^{\circ} \mathrm{C}$ for $8 \mathrm{hr}$. was performed. Table II summarizes the different upsetting conditions and treatments investigated in the present work.

Table II : Upsetting conditions (1) 

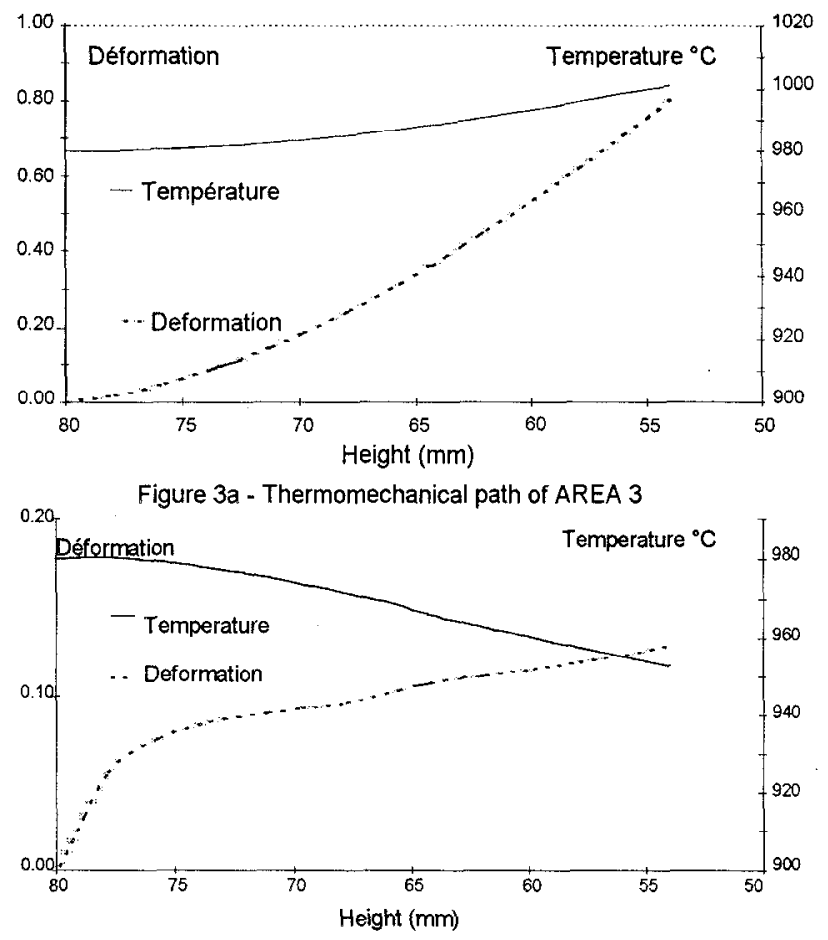

Figure 3B - Themomechanical path of AREA 4

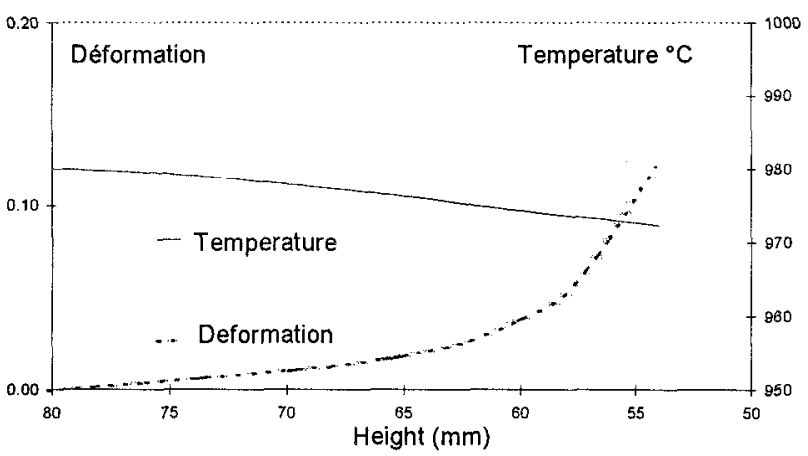

Figure $3 c$ - Thermomechanical path of AREA 1
Three paths representative of the upsetting conditions are shown on Figure 3. Each of these thermal and mechanical paths can be associated with a specific area of the deformed specimens as shown on Figure 4.

These deformation and temperature charts illustrate the variety of different output data which can be obtained from a single upsetting test. To validate the calculations and also to emphasize and analyze more quantitatively the strong influence of insulation and strain rate on local temperature, a thermocouple located at the center of each specimen permitted to measure the instantaneous temperature during upsetting. Table III reports the observed increase in temperature as a function of strain rate and insulation. These data show that the local temperature can be significantly higher than the nominal temperature, even at low deformation rate.

Table III : Temperature increase at specimen center.

\begin{tabular}{|c|c|c|c|}
\hline Strain rate & 0.03 & 0.20 & 0.4 \\
\hline Temperature increase $\Delta \mathrm{T}$ for high insulation & $+13^{\circ} \mathrm{C}$ & $+30^{\circ} \mathrm{C}$ & $+40^{\circ} \mathrm{C}$ \\
\hline$\Delta \mathrm{T}$ for medium insulation & $+10^{\circ} \mathrm{C}$ & & \\
\hline$\Delta \mathrm{T}$ without insulation & $+6^{\circ} \mathrm{C}$ & & \\
\hline
\end{tabular}

For areas labeled 2 and 3, the increase in deformation varies continuously, the path $3 \mathrm{~A}$ is representative of such conditions. For area 4 , illustrated by path $3 \mathrm{~B}$, most of the deformation occurs at the beginning of the upsetting. For area 1 , on the contrary and as shown by path $3 \mathrm{C}$, most of the deformation occurs during the last stage of the upsetting. 


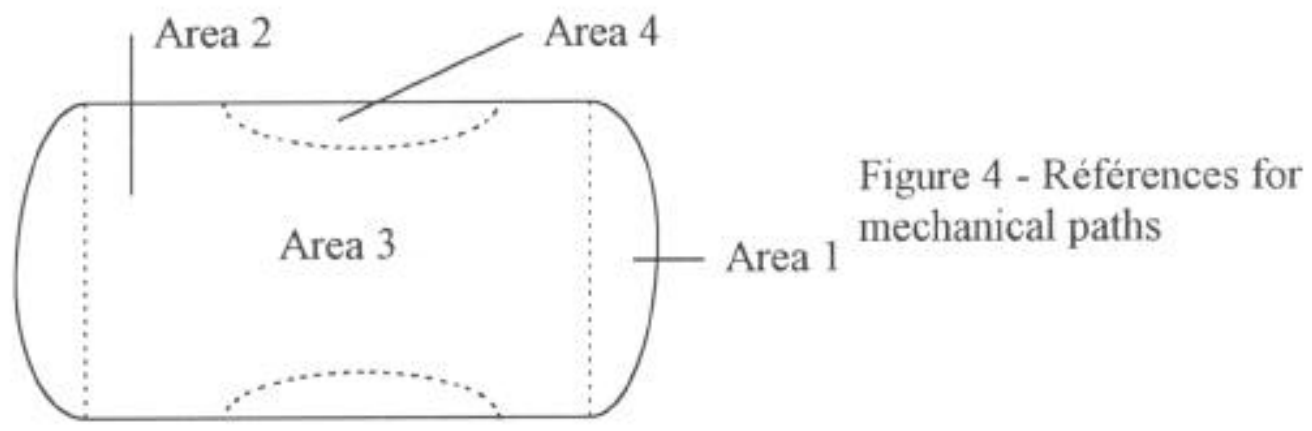

\section{Microstructural observations}

Recrystallisation and grain size.

Microstructure was investigated extensively at the different stages of the process. As an example, Figs. 5a-c show the evolution of the microstructure at the final strain level for a ram speed of $1 \mathrm{~mm} / \mathrm{s}$, without insulation and reheating after the upsetting. These micrographs are in agreement with the usual influence of dynamic recrystallisation, increasing with the strain level and leading to a finer grain size when completed.
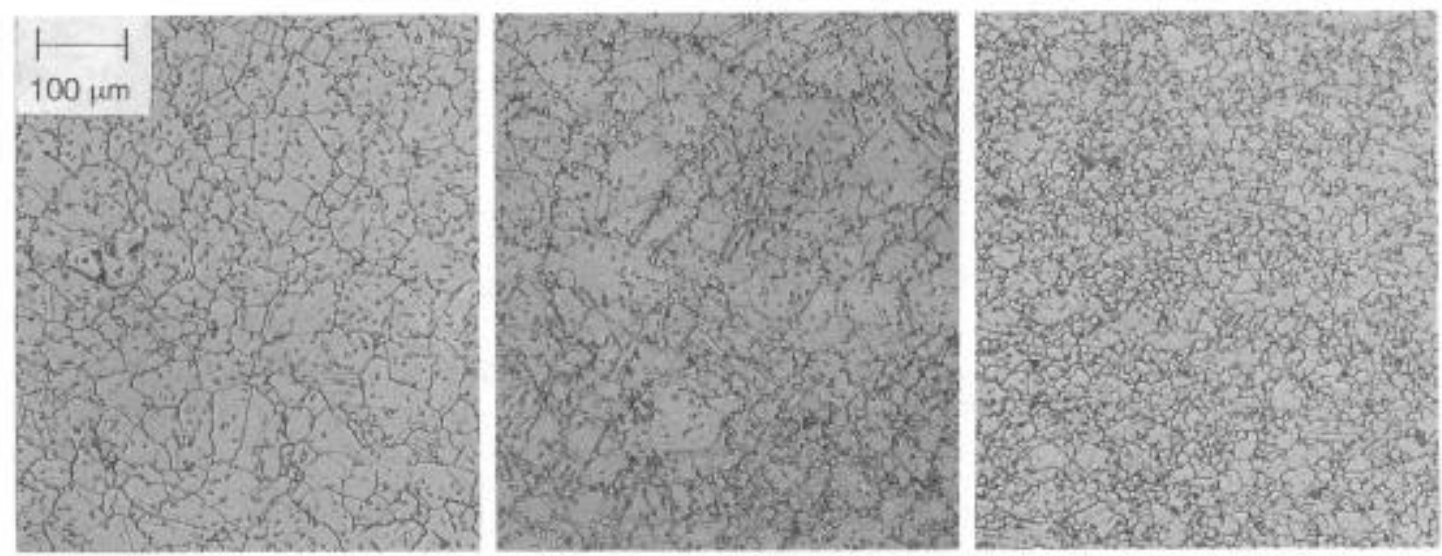

Figure 5 - Evolution of the microstructure with strain level:
5a: $\varepsilon<0.1$
$-5 b: \varepsilon=0.2$
$-5 \mathrm{c} \cdot \varepsilon=0.7$
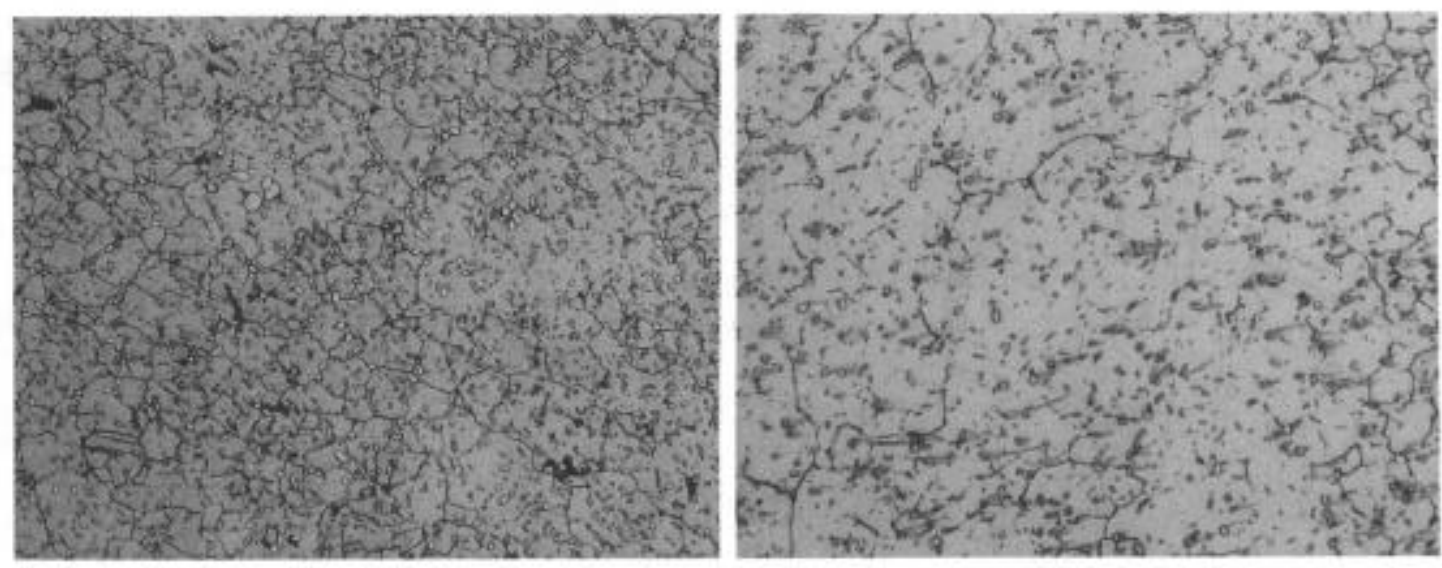

Figure 6 - Evolution of the microstructure with SHT :

6a: at $955^{\circ} \mathrm{C}$

$6 \mathrm{~b}$ at $970^{\circ} \mathrm{C}$ 
After deformation, an additional solution heat treatment at $955^{\circ} \mathrm{C}$, or $970^{\circ} \mathrm{C}$, or else reheating at $980^{\circ} \mathrm{C}$, leads to coarse-grained areas (Fig. 6a and b) systematically located on the same part of the specimens. These critical areas are always located along the frontier between thermomechanical paths characteristic of area 1 and 2.

Figure 7 illustrates the effect of strain $\varepsilon$ on abnormal grain growth. After a solution heat treatment at $970^{\circ} \mathrm{C}$, grain size as large as ASTM 5 is observed within the critical area corresponding to a strain $\varepsilon=0.1$. The same evolution is observed after a heat treatment at $955^{\circ} \mathrm{C}$, but grain size is stabilized at about ASTM 6/7 (Fig. 6a).

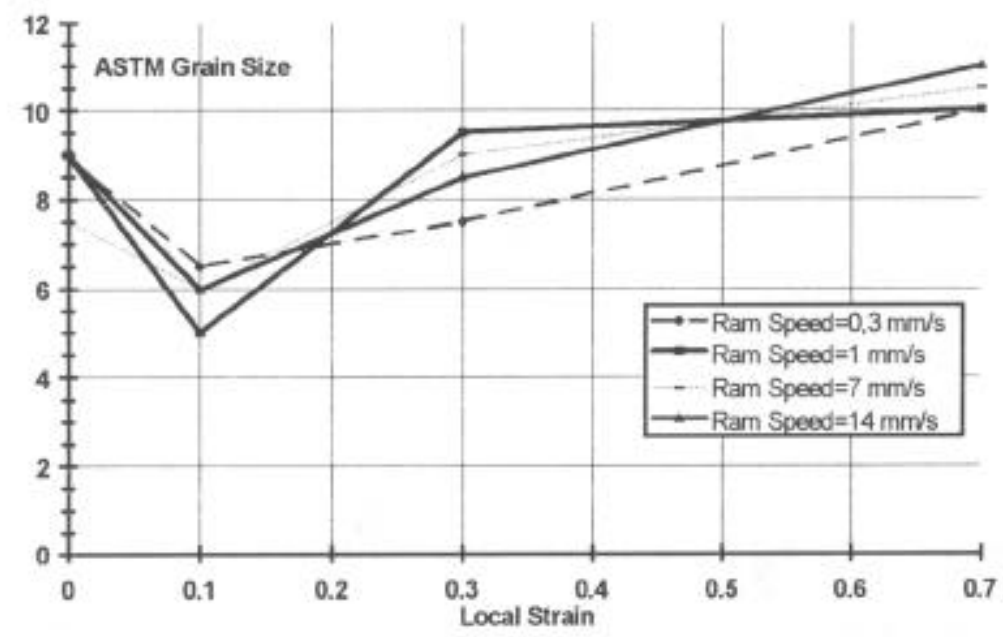

Figure 7 - Effect of Strain on Grain Size

All the considered parameters were found to participate in the observed grain growth. Therefore, the analyze of their combined influence is quite complex and certainly requires many additional experiments. However, for a first estimate, the local strain appears to be the major parameter. Nevertheless, the other parameters acting on the total amount of energy introduced in the material cannot be neglected. For example, a higher strain rate leads to limit the heat losses and to increase the adiabatic heating, and therefore, to increase the level of recrystallisation.

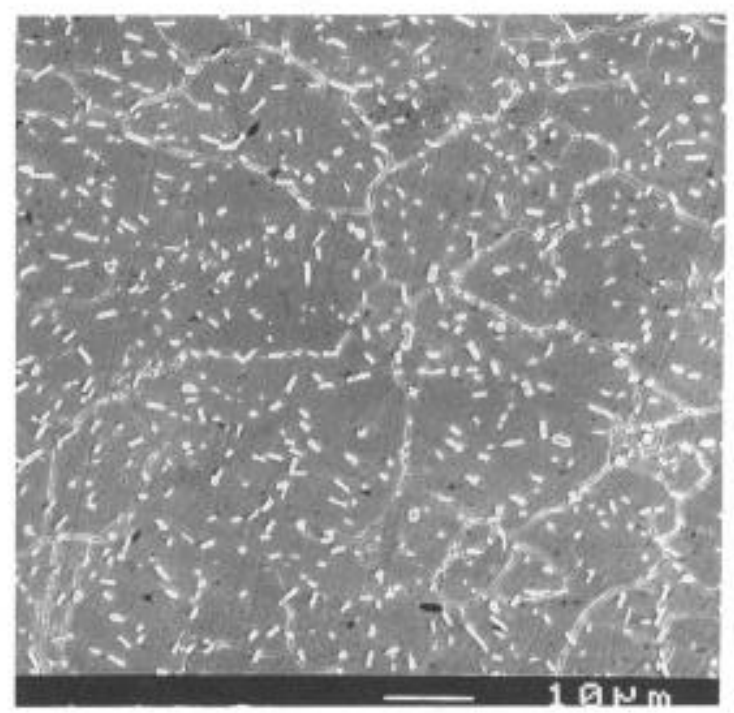

8a : As forged $\varepsilon=0.1$

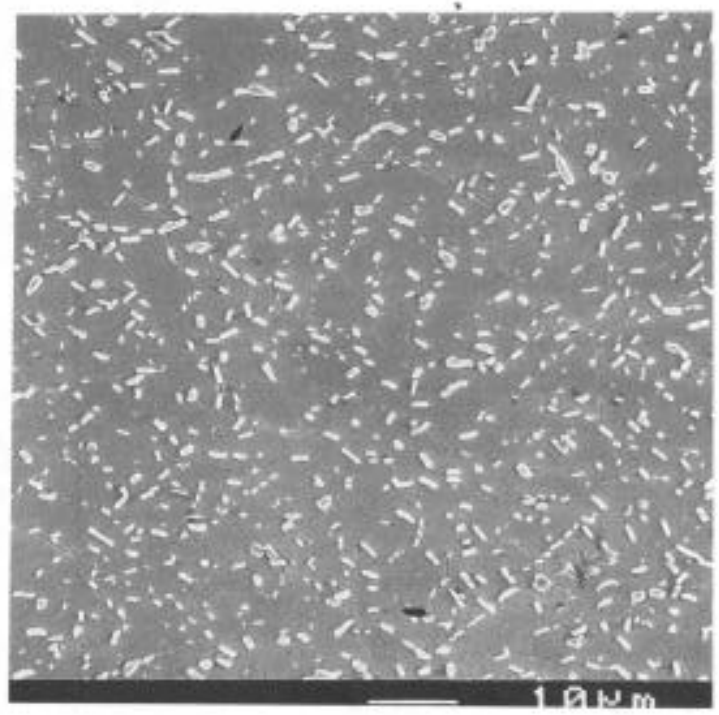

$8 \mathrm{~b}:$ SHT $955^{\circ} \mathrm{C} \varepsilon=0.1$ 


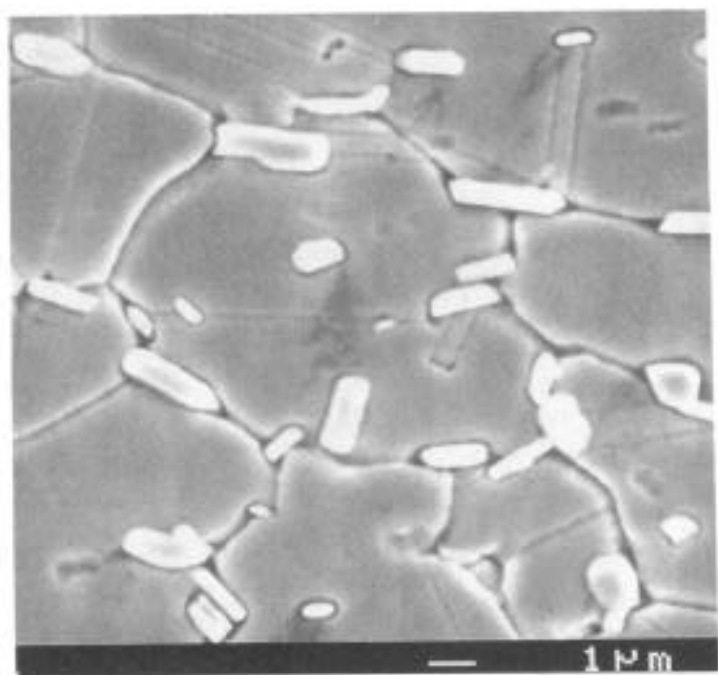

$8 \mathrm{c}:$ As forged $\varepsilon=0.7$

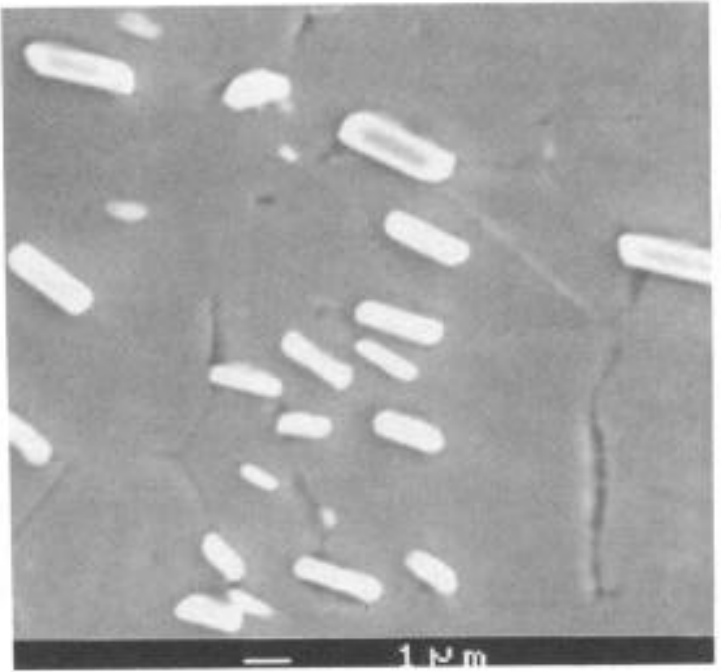

8 d : SHT $970{ }^{\circ} \mathrm{C} \varepsilon=0.7$

Figure 8 - Evolution of the $\delta$ precipitates distribution with SHT

\section{$\delta-\mathrm{Ni}_{3} \mathrm{Nb}$ Precipitates.}

The surface fraction $(\%)$ of $\delta-\mathrm{Ni}_{3} \mathrm{Nb}$ and the number of precipitates per $\mathrm{cm}^{2}$ were determined from surface analysis. The investigated specimens were representative of the three different solution heat treatments, the results are summarized in Table IV.

Table IV : Distribution of $\delta-\mathrm{Ni}_{3} \mathrm{Nb}$ precipitates

\begin{tabular}{|c|c|c|c|}
\hline $\begin{array}{l}\text { Specimen } \\
\text { conditions }\end{array}$ & $\begin{array}{l}\text { Area location and } \\
\text { local strain }\end{array}$ & $\begin{array}{c}\text { Surface fraction }(\%) \\
\text { of } \delta-\mathrm{Ni}_{3} \mathrm{Nb}\end{array}$ & $\begin{array}{l}\text { Number of } \delta-\mathrm{Ni}_{3} \mathrm{Nb} \\
\text { precipitates per } \mathrm{cm}^{2}\end{array}$ \\
\hline As forged & $1: \varepsilon<0.1$ & 9.8 & 43 \\
\hline " & $1 \mathrm{~A}: \varepsilon=0.1$ & 9.1 & 40 \\
\hline " & $3: \varepsilon=0.7$ & 10.2 & 37.5 \\
\hline SHT at $955^{\circ} \mathrm{C}$ & 1: $\varepsilon<0.1$ & 13.6 & 66 \\
\hline$\ll$ & $1 \mathrm{~A}: \varepsilon=0.1$ & 12.3 & 52 \\
\hline « & $3: \varepsilon=0.7$ & 12,0 & 65 \\
\hline SHT at $970^{\circ} \mathrm{C}$ & $1: \varepsilon<0.1$ & 8.4 & 42 \\
\hline 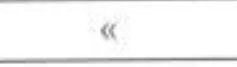 & $1 \mathrm{~A}: \varepsilon=0.1$ & 9.1 & 35 \\
\hline « & $3: \varepsilon=0.7$ & 9.9 & 36 \\
\hline
\end{tabular}

The morphology and distribution of $\delta-\mathrm{Ni}_{3} \mathrm{Nb}$ precipitates are illustrated on Fig. 8a-d for the different SHT and strains. At different locations, particularly those where the grain growth occurred, no major difference in surface fraction or morphology of $\delta$ - $\mathrm{Ni}_{3} \mathrm{Nb}$ precipitates was detected. An additional precipitation of $\delta-\mathrm{Ni}_{3} \mathrm{Nb}$ particles at $955^{\circ} \mathrm{C}$, corresponding to an increase in surface fraction of about $4 \%$, permits to limit the secondary grain growth to grain sizes which do not exceed an ASTM index of about 6/7. However, in the critical area, most of the $\delta-\mathrm{Ni}_{3} \mathrm{Nb}$ precipitates are intragranular, so that grain boundaries motion would be easier, but certainly remain partially limited by the network of $\delta-\mathrm{Ni}_{3} \mathrm{Nb}$ precipitates. 


\section{Mechanical properties}

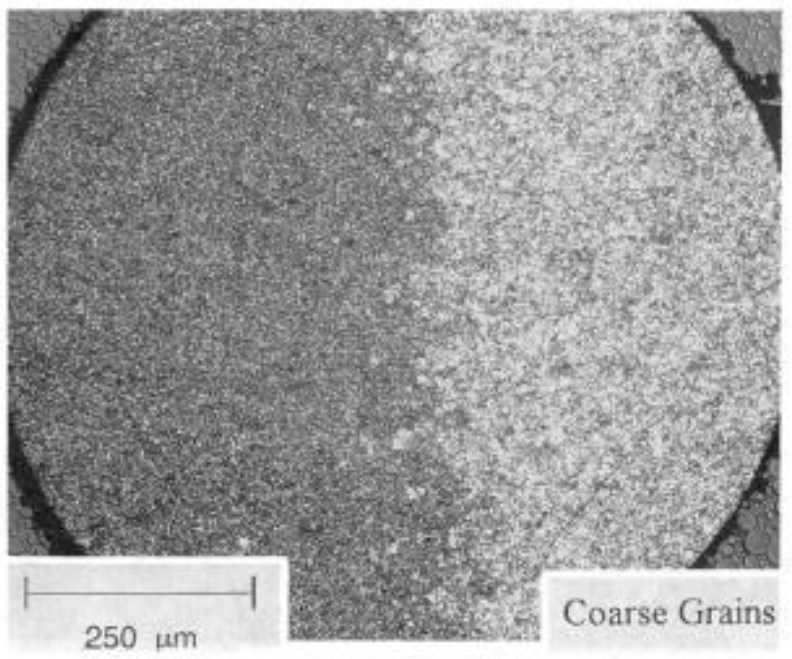

Tensile strength

Tensile tests were performed to attempt to correlate the microstructure, and particularly the fraction of coarse grains, to the resulting mechanical properties. The tests were performed at room temperature, the yield strength at $0.2 \%,(\mathrm{YS})$, and the ultimate tensile strength (UTS) were the parameters chosen to compare the different microstructure. All the specimens were cut parallel to the long axis of the specimens, the location of the test specimen axis was chosen to have a given microstructure, as uniform as possible, in the active part of the test specimens

\section{Figure 9 - Example of a $40 \%$ fraction of coarse grains in tensile specimen}

They all received the classical double aging heat treatment at 720 and $620^{\circ} \mathrm{C}$ for $8 \mathrm{hr}$. A total of eight different microstructures were tested, the corresponding test specimens were classified relatively to their surface fraction of coarse grains; an example is shown in Fig. 9.

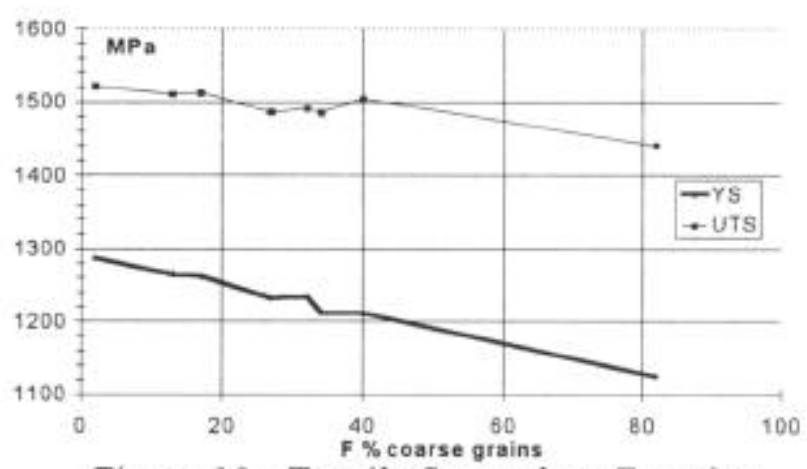

Figure 10 - Tensile Strength as Function of $\%$ Coarse Grains

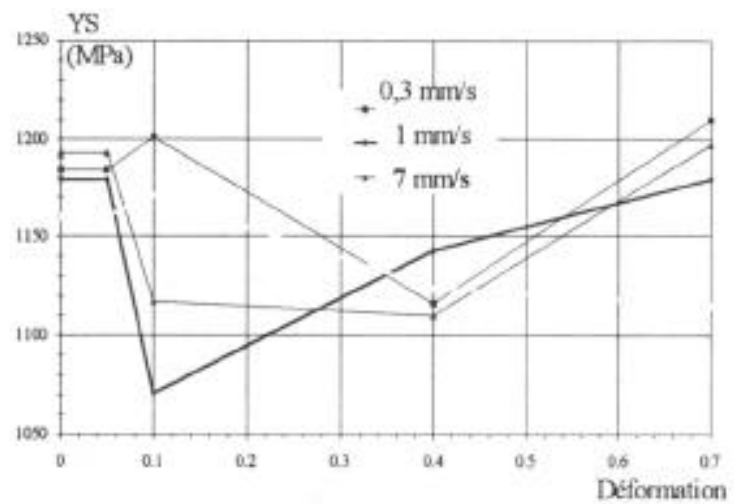

Figure 11 - Influence of the Deformation on the Yield strength at RT for different Ram Speeds
The evolution of YS and UTS as a function of the fraction of coarse grains is reported on Figure 10. A drop in yield strength appears as soon as the coarse grains are predominant in the active section.

Figure 11 illustrates the variation of yield strength as a function of strain level and strain rate. A greater dispersion was observed for the critical strain $\varepsilon=0.1$, with a minimum for the ram speed of 1 $\mathrm{mm} / \mathrm{s}$. From the influence of the fraction of coarse grains on the yield strength, the variation in yield strength must be corrected by a factor which also depends on this fraction. Nevertheless, the phenomena was not clearly located at the level of $\varepsilon=0.1$. An interesting result, worth to be noted, is the significantly lower yield strength associated with the higher strain and strain rate $(\varepsilon=0.7$ and $\mathrm{v}=7 \mathrm{~mm} / \mathrm{s}$ )

This low yield strength could be attributed to a highly recrystallized microstructure and a low density of dislocations. 


\section{Low Cycle Fatigue properties}

Similarly to tensile tests, fatigue tests were performed to determine the influence of coarse grains on the fatigue lifetime. These fatigue tests were made at $350^{\circ} \mathrm{C}$ for a stress ratio $\mathrm{R}=0$, a sinusoidal wave form and two levels of total strain $\Delta \varepsilon$ respectively equal to 0.50 and 0.56 .

These results were compared to well established average curves

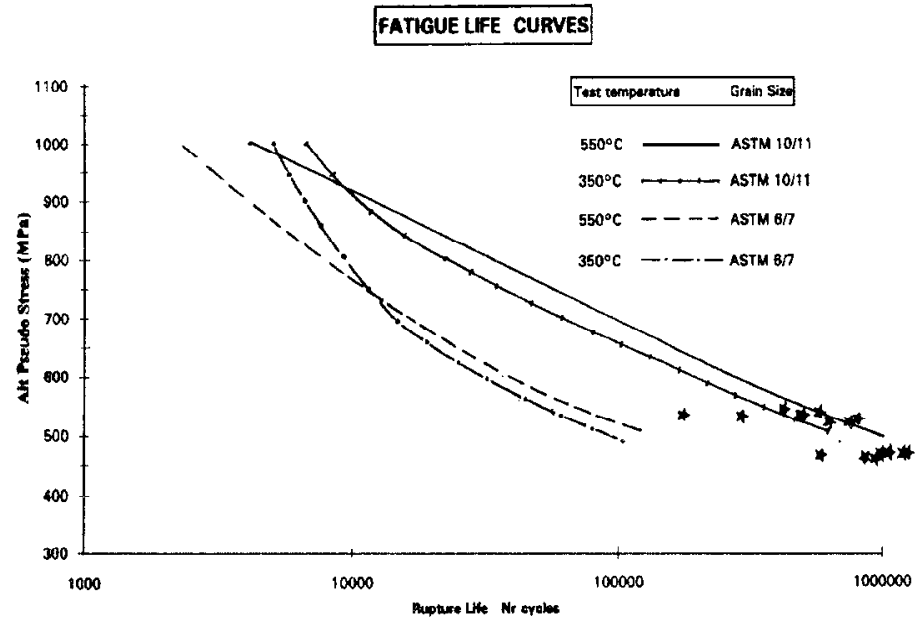

(4) relating the equivalent stress $\Delta \varepsilon^{*} \mathrm{E} / 2$ ( $\mathrm{E}$ is the Young modulus) to the fatigue life $(\mathrm{Nr})$. These average curves were determined for different temperatures and grain sizes, but all the specimens showed the same microstructure made of equiaxed grains and intergranular precipitates of $\delta$ $\mathrm{Ni3} \mathrm{Nb}$. The average curves and the experimental data are reported on Fig 12. The comparison with the average

Figure 12 - Fatigue properties as a function of the Grain Size

curves shows that the measured fatigue life corresponds to a grain size population of ASTM 8 to 10. Therefore, for this specific microstructure characterized by an intragranular distribution of $\delta$ precipitates, the grain size has a less important impact on fatigue properties. Twinned grains of average size ASTM 5-6 with intragranular $\delta$ precipitates lead to fatigue properties equivalent to that of the specimens, with a fully equiaxed microstructure of ASTM 8-10 and intergranular $\delta$ precipitates.

\section{Conclusions}

Abnormal grain growth occurs during forging and SHT of alloy 718 for specific conditions. The present work permitted a first analysis on this phenomenon, of the rôle of thermal insulation, strain rate, local strain and temperature. For the geometry of the test specimens considered during this work, such a grain growth occurs preferentially in area continuously strained, at approximately constant strain rate and for a local strain of about 0.1 . The fraction of coarse grained area and the corresponding grain size depends on the thermal cycles during forging and heat treatment. The control of thermal insulation and temperature of SHT would allow to limit their extend and their intensity. These coarse grained areas induce a decrease of about 10 to 15 $\%$ in yield strength. Fatigue tests showed that the fatigue life is apparently not affected by the presence of large twinned grains containing intragranular precipitates of $\delta \mathrm{Ni3} \mathrm{Nb}$. Further work is still in progress to accurately characterize the initiation and intensity of this abnormal grain growth. This will be done by a modeling of this specific area with different geometry. Furthermore, it is important to apply these results to engine disks in order to smooth this local grain growth and move its location to designated areas, or outside of the finished part. 


\section{$\underline{\text { References }}$}

1 - N. A ; Wilkinson, "Forging of 718 - the importance of T.M.P », Superalloy 718: Metallurgy and application (E.A. Loria TMS, 1989), 119-133

2 - D Zhao, P. K. Chaudhury, « Effect of starting grain size on as-deformed microstructure in high temperature deformation of alloy $718 »$ Superalloys $718,625,706$ and various derivatives (E. A. Loria TMS, 1994), 303-315

3 - P. E. Mosser et al , »Metallurgical aspects of forge modeling in alloy $718 »$, Superalloy 718 : Metallurgy and application (E.A. Loria TMS, 1989), 179-188

4 - B. Pieraggi, J.F. Uginet, «Fatigue and creep properties in relation with alloy 718 microstructure », Superalloys $718,625,706$ and various derivatives (E. A. Loria TMS, 1994), $535-544$ 